\title{
"Teachers Skills Competence, Learners Satisfaction and Psychomotor Performance in Cookery NC II"
}

\author{
Melodina V. Biadnes* \\ a melodina.biadnes@deped.gov.ph \\ Dumalinao National High ,Paglaum DUmalinao Zamboanga Del Sur ,7016, Philippines \\ Block 11 lot 21 Phase II Kgawasan Village Subdivsion, Pagadian City 7016,Philippines
}

\begin{abstract}
Competent teachers are the most critical piece in improving students' achievement and closing the achievement gap. The single most important influence on student learning is the quality of teaching, yet most schools do not define what good teaching is (Danielson, 2006).

Notably, Fong-Yee and Normore (2013) highlighted that factors such as teachers' cognitive ability, subject matter knowledge, knowledge of teaching and learning, licensure, and teaching behaviors in the classroom are related to teacher quality and increased student achievement.

On the basis of the Zamboanga del Sur Division Memorandum No. 15, s.2015, it is interesting to note that teachers are called for skills training for public secondary TLE teachers to provide opportunities to hone their technical skills in preparation for the required and mandatory assessment and certification by the Technical Education Skills Development Authority (TESDA

Thus, the study was conducted to examine teachers' competence in teaching cookery and to explore its relationship to the students' skills performance in the context of Zamboanga del Sur. Moreover, outcome of this study will serve as a basis for curriculum enhancement to improve training experience in Cookery NCII which will be handled by TLE teachers in order to enhance their competence in cookery NCII which manifested to the satisfaction and psychomotor performance among learners.
\end{abstract}




\section{Introduction}

Competent teachers are the most critical piece in improving students' achievement and closing the achievement gap. The single most important influence on student learning is the quality of teaching, yet most schools do not define what good teaching is (Danielson, 2006).

Notably, Fong-Yee and Normore (2013) highlighted that factors such as teachers' cognitive ability, subject matter knowledge, knowledge of teaching and learning, licensure, and teaching behaviors in the classroom are related to teacher quality and increased student achievement.

On the basis of the Zamboanga del Sur Division Memorandum No. 15, s.2015, it is interesting to note that teachers are called for skills training for public secondary TLE teachers to provide opportunities to hone their technical skills in preparation for the required and mandatory assessment and certification by the Technical Education Skills Development Authority (TESDA).

For the purpose of the following standards, Hartmann (2014) underscored that cooking classes in schools provide a great opportunity to raise awareness of fresh foods, food ingredients, and health-promoting diets. These classes could also provide students with the skills on how to economically and quickly prepare healthy dishes.

Admittedly, Lavelle et. al (2016) proffered that cooking is a valuable life skill which is often linked with improved diet quality, such as improving the uptake of fruit and vegetables and an increased recognition of healthier foods.

Several studies have been conducted to measure the level of student satisfaction in traditional and online environments. Dziuban, Wang, and Cook (2004) concluded that students were more likely to evaluate courses and instructors with satisfactory ratings if they believed their professors communicated effectively, facilitated or encouraged their learning, organized the course effectively, showed interest in students' learning and progress, demonstrated respect for students, and evaluated students' work accurately. Marsh and Roche (1997) developed a complex model for defining student perceptions of satisfaction in terms of several factors: learning value, instructor enthusiasm, rapport, organization, interaction, coverage, and assessment. Another study found that students who participated in cohorts with other colleagues and received detailed feedback from and interaction with faculty reported satisfaction with their learning experiences (Shea, Fredericksen, Pickett, \& Pelz, 2003).

According to Rezaeinejad and company (2015), a learning process is indispensable in human life. Students' learning styles are acquired when the learner started to engage himself in the learning environment. The teachers and other factors contribute to the creation of a child's model of learning. When students get a failing grade, failure in meeting their learning preferences is always pointed out as the reason. In the study of Tulbure (2011) about the learners' learning modality and other related variables investigating their relationship to the students' grade point average, find out the relevant variations between the two identified sets of tertiary education learners base on their responses to the teaching strategies that match up to their learning styles. The difference was that slow learners learning styles when attended to helped them in their academic performance while fast learners do not need learning styles to improve their performances. Today's learners are so much different compared to the types of learners the country had a decade ago due to the fast changing environment and culture. They may vary in learning styles compared to that of their parents and 
teachers. Filipinos may vary in learning styles. This issue drives the researcher to verify the learning preference of the students and would try to clarify whether each type of learner uses a learning style specific only to them. However, there is no publication that identifies the learning style that is specific only to each type of learners.

Thus, the study was conducted to examine teachers' competence in teaching cookery and to explore its relationship to the students' skills performance in the context of Zamboanga del Sur. Moreover, outcome of this study will serve as a basis for curriculum enhancement to improve training experience in Cookery NCII which will be handled by TLE teachers in order to enhance their competence in cookery NCII which manifested to the satisfaction and psychomotor performance among learners.

\section{Statement of the Problem}

This study aimed to examine teacher's competence in teaching Cookery on Technology Vocational and Livelihood (TVL) and its relationship to the students' skills performance on the selected schools of Dumalinao District, Zamboanga Del Sur, and School Year-2021

- What are the teachers' competences in teaching Cookery NCII in terms of basic, common and core competencies?

- What is the learner's satisfaction in teachers' competency in Cookery NCII?

- Is there a significant relationship between the teachers' skills competence in Cookery NCII, and, learner's satisfaction?

\section{Scope of the Study}

This study focused on the teachers' competence in teaching Cookery NCII and its learners' satisfaction \& psychomotor performance. Teachers' competencies in teaching cookery is determined based from the unit codes of the National Certification II in Cookery set by the Technical Education and Skills Development Authority such as basic, common and core units of competencies.

\section{Research Design}

This study utilized the descriptive - quantitative which is appropriate to determine the teachers' competence in Cookery NCII and students' skills performance through a survey questionnaire.

It described teachers' competences in teaching Cookery NCII in terms of basic, common and core competencies. Then, it determined learner's satisfaction and psychomotor performance in TLE-Cookery based on their average grade during $1^{\text {st }}$ and $2^{\text {nd }}$ grading period of School Year 2020-2021. Also, it is also a correlational approach since it explored the relationship between the teachers' competence in teaching cookery NCII as rated by respondents to the learners' satisfaction and psychomotor performance. Then, it utilizes comparative approach since this study tries to find out the difference on the teachers' competence in TVL-Cookery as rated by respondents when grouped according to their profile. 


\section{Population Sampling Design}

The researchers employed a non-probability using a purposive sampling design in the selection of the respondent-schools covered in this study. It is purposive because 8 schools in the district are included in this study and identified schools in the mainland with same size will be part of the study. The schools were classified into small, medium, large and extra-large schools.

\section{Instruments}

The research instrument utilized in this study is a modified survey-questionnaire based on the Self Assessment Guide (SAG) questionnaire issued by TESDA which entails the unit of competencies prescribed for National Certification II in Cookery set by the Technical Education and Skills Development Authority such as basic, common and core units of competencies which can be used to determine teachers' competence in Teaching Cookery NCII which will be rated by randomly selected Grade 12 students. Moreover, the statement used on the said instrument was also taken from the $\mathrm{K}$ to 12 Home Economics - Cookery Curriculum Guide dated December 2013.

\section{Ethical Consideration}

The study was guided with appropriate research ethics and guidelines. Primary and secondary data were used in this study. Consent from the respondents was taken and appropriate permission was also ensured for usage of their given data. Confidentiality of the respondents was maintained strictly to ensure privacy of the respondents. The disclosure of respondent identity was based on their permission if they are not willing to disclose identity. Their identity was not exhibited. Beyond the fact, usage of any secondary from any source was acknowledged with appropriate reference. Hence the ethical aspect of research was followed very strictly in this research. The researchers sought approval of the respondents to allow the researchers to present in the other forum or fora.

\section{Data Gathering Procedure}

The researcher prepared a letter addressed to the Schools Division Superintendent of Zamboanga del Sur for approval on the conduct the study. After which, the same letter will be presented to the principal of each school for concurrence and approval. With their authority, respondents were gathered for an immediate distribution of the survey questionnaires. After the data gathering, the responses were treated statistically. 


\section{Data Analysis}

- What are the teachers' competences in teaching Cookery NCII in terms of basic competencies, common competencies and core competencies

Table 1

Teachers' Basic Competences in Teaching Cookery as rated by the respondents Statements

\section{Mean}

1. explain concepts in cookery and discuss the relevance of the course

2. explore career opportunities in cookery

3. to identify areas for improvement, development and growth

4. align our personal entrepreneurial competencies according to our career choice

5. create a plan of action that ensures success of our business/ career choice.

6. explain how different factors influence the business environment.

7. explain procedures for generating business ideas or identify business opportunities.

8. identify the chemicals to be utilized in cleaning and sanitizing kitchen tools and equipment

9. prepare cleaning agents in accordance with manufacturer's instructions

10. clean and sanitize kitchen tools in accordance with prescribed standards
Std.

Deviation

3.17

3.14

.58

.65
Evident

Evident

Legend: Highly Evident $(\mathrm{HE})=3.50-4.00$; Evident $(\mathrm{E})=2.50-3.49$; Less Evident $(\mathrm{LE})=1.50-2.49$;

Table 1 presents the statements on the teachers' basic competences in teaching Technical Vocational Livelihood- Cookery as rated by the respondents. It shows that the respondents obtained a highest mean of 3.50 in the statement "explain concepts in cookery and discuss the relevance of the course," then 3.35 in the statement "clean and sanitize kitchen tools in accordance with prescribed standards," while 3.34 in the statement "explore career opportunities in cookery," and 3.32 in the statement "identify the chemicals to be utilized in cleaning and sanitizing kitchen tools and equipment." The above mentioned statements were described as "evident."

Similarly, statements got a mean of 3.22, "prepare cleaning agents in accordance with manufacturer's instructions," 3.17 "identify areas for improvement, development and growth," 3.15 "create a plan of action that ensures success of our business/ career choice," 3.14 "align our personal entrepreneurial competencies according to our career choice," 3.10 "explain procedures for generating business ideas or identify business opportunities" and 3.08 "explain how different factors influence the business environment." 
These statements give a descriptive rating of "evident" Hence; it gives an overall weighted mean of 3.24 with its descriptive rating of "evident."

On the other hand, the least priority basic competence among teachers were derived as follows: 1) following instructions on the preparation of cleaning agents; 2) identifying areas for improvement; 3 ) creating plan of action; and 4) engaging oneself to entrepreneurship. It implies that majority of the teachers performed the basic competencies that students needs to learn to complete the qualification in TESDA for assessment.

Table 2

Teachers' Common Competences in Teaching Cookery as rated by the respondents Statements

Mean

3.38

3.36

3.26

2.88

3.21

3.18

2.96

Std.

Deviation

.60

escriptive

1. store cleaned kitchen tools and equipment safely in the designated space

with food safety and occupational health regulations

3. follow workplace safety procedures

following standard procedures.

5. observe sanitary practices in presenting appetizers

6. keep appetizers in appropriate conditions to maintain their freshness, quality, and taste.

7. demonstrate vegetable storage in accordance with FIFO operating procedures

8. apply creativity and innovative techniques to develop marketable product

9. employ a unique selling proposition to the product or service

10. select packaging materials in accordance with enterprise standards

Overall Weighted Mean

\subsection{1}

3.13
.61

.65

.80

Evident

.64

Evident

.63

Evident

.66

Evident

.66

Evident

Evident

.68

Evident

.37

Legend: Highly Evident $(H E)=3.50-4.00 ;$ Evident $(E)=2.50-3.49 ;$ Less Evident $(L E)=1.50-2.49 ;$ Not Evident

Table 2 indicates statements on the teachers' common competences in teaching Technology Livelihood Education in Cookery as rated by the respondents. It shows that respondents obtained mean of 3.38 "store cleaned kitchen tools and equipment safely in the designated space;" 3.36 "clean the kitchen area hygienically in accordance with food safety and occupational health regulations;" 3.26 "follow workplace safety procedures;" 3.21 "observe sanitary practices in presenting appetizers;" 3.18 "keep appetizers in appropriate conditions to maintain their freshness, quality, and taste;" 3.10 "select packaging materials in accordance with enterprise standards;" 3.01 "apply creativity and innovative techniques to develop marketable product;" 2.96 "demonstrate vegetable storage in accordance with FIFO operating procedures;" and 2.95 "employ a unique selling proposition to the product or service." The following statements were 
described as "evident." It also got an overall average mean of 3.13 with a descriptive rating of "evident."

Table 3

\section{Teachers' Core Competences in Teaching Cookery as rated by the respondents}

\section{Statements}

1. prepare a variety of appetizers

2. prepare and present a variety of salads and dressings attractively

3. prepare an present a variety of sandwiches attractively

4. prepare variety of desserts and sauces using sanitary practices

5. identify factors in plating and presenting desserts

6. present egg dishes hygienically and attractively using suitable garnishing and side dishes sequentially within the required time frame

7. present starch dishes with suitable plating and garnishing according to standards

8. cook variety of vegetable dishes following appropriate cooking methods to preserve optimum quality and nutrition

9. prepare suitable sauces and accompaniment in serving vegetable dishes

10. perform guidelines in serving fish and seafood dishes.

\section{Overall Weighted Mean}

Mean

3.24

3.21

3.14

3.07

3.04
Std. Deviation

.68

.35
Descriptive

Rating

Evident

Evident

Evident

Evident

Evident

Evident

Evident

Evident

Legend: Highly Evident $(\mathrm{HE})=3.50-4.00 ;$ Evident $(\mathrm{E})=2.50-3.49 ;$ Less Evident $(\mathrm{LE})=1.50-2.49 ;$ Not Evident $(\mathrm{NE})=1.00-1.49$

Table 3 represents statements on the teachers' core competences in teaching Technology Livelihood Education in Cookery as rated by the respondents. It shows that respondents got a similar mean of 3.24 on statements prepare a variety of appetizers and prepare variety of desserts and sauces using sanitary practices. Whereas, a mean of 3.22 "prepare an present a variety of sandwiches attractively", 3.21 "prepare and present a variety of salads and dressings attractively," 3.14 "identify factors in plating and presenting desserts," 3.07 "present egg dishes hygienically and attractively using suitable garnishing and side dishes sequentially within the required time frame," 2.98 "present starch dishes with suitable plating and garnishing according to standards," 2.95 "cook variety of vegetable dishes following appropriate cooking methods to preserve optimum quality and nutrition," 2.81 "prepare suitable sauces and accompaniment in serving vegetable dishes," 2.56 "perform guidelines in serving fish and seafood dishes." It got an overall average mean of 3.04 
with a descriptive rating of evident.

It can be noted that the respondents were able to perform the different core competencies in first and second quarter. It implies further that teachers meet the very important part of the qualifications for assessment in TESDA that students must achieve particularly on the core competencies in order for them to pass and obtain a National Certificate II (NCII) in Cookery.

Table 4

\section{Summary of Teachers' Competences in Teaching TVL Education - Cookery as rated by the respondents}

\begin{tabular}{lcccc}
\multicolumn{1}{c}{ Competencies } & Mean & $\begin{array}{c}\text { Std. } \\
\text { Deviation }\end{array}$ & Descriptive Rating & $\begin{array}{c}\text { Verbal } \\
\text { Interpretation }\end{array}$ \\
Basic & 3.24 & .59 & Evident & High \\
Common & 3.21 & .66 & Evident & High \\
Core & 3.22 & .69 & Evident & High \\
$\quad$ Overall Weighted Mean & $\mathbf{3 . 0 4}$ & $\mathbf{. 3 5}$ & Evident & High
\end{tabular}

Legend: Highly Evident $(\mathrm{HE})=3.50-4.00=$ Very High ; Evident $(\mathrm{E})=2.50-3.49=$ High $;$ Less Evident $($ LE $)=1.50-2.49=$ Low $;$ Not Evident $(\mathrm{NE})=1.00-1.49=$

Table 6 shows the summary on the teachers' core competences in teaching Technology Livelihood Education in Cookery as rated by the respondents. It shows that respondents got mean scores of 3.24, 3.21 and 3.22 in basic, common and core competences respectively which were described as "evident" with equivalent verbal interpretation of "high."

In sum, it indicated an overall weighted mean of 3.04 which is described as evident with a verbal interpretation of high. It means that teachers' competences are high; hence, they exhibit a good performance in teaching Cookery.

Problem 2: Is there a significant relationship between the teachers' skills competence in Cookery NCII, and, learner's satisfaction?

Table 5

Correlation: Teachers' Competence and the Students' Skills Performance in TVL-Cookery

Variables

Teachers' Competence and

Learner Skills Performance in TLE -Cookery

$(*$ significant at alpha $=0.05)$

Table 4 presents the correlation between the teachers' competence and the students' skills performance in TVL-Cookery. It shows that the coefficient of correlation of 0.365 with the corresponding probability value of 0.00 is significant at alpha $=0.05$. It means that there was a significant relationship between the teachers' competence and students' skills performance in TVL-Cookery. Therefore, the null 
hypothesis is rejected since the $\mathrm{p}$-value is lesser the value of alpha $=0.05$. In addition, there is a moderately low correlation between the teachers' competence and the students' skills performance in TVL-Cookery.

Thus, when teachers' competences are very high then students' skills performances are expected to be outstanding. However, if teachers' competence is very low then students' skills performances are expected not to meet the expectations which holds true based on the data presented.

In this case, data revealed that teachers' competences were rated high by students' who got very satisfactory performance. This implies that the knowledge and skills of students are based on the background knowledge of the teachers. If teachers lack knowledge on the subject being taught to the students, there is a tendency that performances of the students are low and limited only. As supported by Muzenda (2013) who deduced that provision of training to teachers on the specified components of lecturer competence can effectively improve quality of teaching learning towards attainment of high students' academic performances.

Problem 3: Is there a significant relationship between the teachers' skills competence in Cookery NCII, and, learner's satisfaction?

Table 5

Correlation: Teachers' Competence and the Students' Skills Performance in TVL-Cookery

Variables

Teachers' Competence and

Learner Skills Performance in TLE -Cookery

\author{
Coefficient of \\ Correlation (r)
}

0.365
Probability Value Interpretation

(p)

0.00

Significant

$(*$ significant at alpha $=0.05)$

Table 5 presents the correlation between the teachers' competence and the students' skills performance in TVL-Cookery. It shows that the coefficient of correlation of 0.365 with the corresponding probability value of 0.00 is significant at alpha $=0.05$. It means that there was a significant relationship between the teachers' competence and students' skills performance in TVL-Cookery. Therefore, the null hypothesis is rejected since the $\mathrm{p}$-value is lesser the value of alpha $=0.05$. In addition, there is a moderately low correlation between the teachers' competence and the students' skills performance in TVL-Cookery.

Thus, when teachers' competences are very high then students' skills performances are expected to be outstanding. However, if teachers' competence is very low then students' skills performances are expected not to meet the expectations which holds true based on the data presented.

In this case, data revealed that teachers' competences were rated high by students' who got very satisfactory performance. This implies that the knowledge and skills of students are based on the background knowledge of the teachers. If teachers lack knowledge on the subject being taught to the students, there is a tendency that performances of the students are low and limited only. As supported by Muzenda (2013) who deduced that provision of training to teachers on the specified components of lecturer competence can effectively improve quality of teaching learning towards attainment of high students' academic performances. 


\section{Conclusion}

\section{Based on the findings, the following conclusions were drawn:}

- Senior High School students who rated their teachers are female Bisayan whose earnings ranged from Php. 1,001 to 5,000.

- Senior High School students gave a rate on their teachers' basic, common and core competence as evident.

- Senior High School students obtained a very satisfactory skills performance in TVL-Cookery.

- Teachers' competence and students' skills performance in TVL-Cookery are correlated.

- The teachers' competences in TVL-Cookery as rated by the respondents differ with sex and ethnicity; however, do not differ on family monthly income.

- The skills performance in TVL-Cookery among respondents differs with sex and family monthly income, however, do not differ on ethnicity.

\section{Recommendations}

Based on the findings and conclusions, the following recommendations are hereby presented:

- To the Department of Education officials

Who are responsible for hiring of teachers, may be guided to determine the needs in every school.

- To the School heads

May be guided in their recommendation with the needed teachers in line with the field of specialization. They may also suggest and promote enhancement of professional development among teachers.

\section{- To the TVL teachers}

May realize the importance of their expertise or competence in the field of specialization which contribute factors to students' skills performance.

\section{- To the Cookery students}

May find it useful for them to learn more and be motivated to learn how to cook through their teachers' enhancement of instruction. 


\section{Acknowledgements}

To God be the Glory, for all the strength, intellect and firmness He has given to me to finish my manuscript.

The researcher wants to give her overwhelming thanks to all people who showed their love, support and guidance in doing her study. These special people are the following, to wit:

Mr. Alhadzmar Lantaka the research professor, for the encouragement, pieces of advice, and sharing his knowledge and expertise to finish this study as our requirements of the subject .

The research participants, for allowing their requested participation in the completion of this research;

Co-teachers and friends for the moral support; and

Loving family, for their pieces of advice, endless love, prayers, untiring, moral and financial support.

\section{References}

Akifyeva, A. \& Alieva, A. (2018). The Infuence of Student Ethnicity on Teacher Expectations and Teacher Perceptions of Warmth and Competence. Psychology in Russia: State of the Art. Volume 11, Issue 1, 2018

Beltran, C. (2017). Factors Affecting Performance of Teachers Teaching in the Senior High School in Labuan District. Unpublished Masters Thesis. Western Mindanao State University

Bernardo, G., Jomori, M., Fernandes, A., Colussi, C., Condrasky, M. and Proença, R. (2018). Positive impact of a cooking skills intervention among Brazilian university students: Six months follow-up of a randomized controlled trial, Appetite, 10.1016/j.appet.2018.08.014, 130, (247-255) 